Check for updates

Cite this: RSC Adv., 2019, 9, 1147

Received 30th October 2018

Accepted 23rd December 2018

DOI: $10.1039 / \mathrm{c} 8 \mathrm{ra0} 0867 \mathrm{a}$

rsc.li/rsc-advances

\title{
A FRET based ratiometric fluorescent probe for detection of sulfite in food $\uparrow$
}

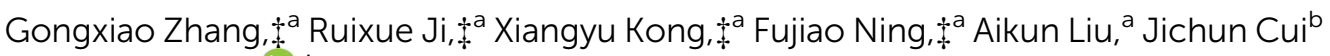 \\ and Yanqing $\mathrm{Ge}$ (iD *a
}

A new fluorophore pyrido[1,2-a]benzimidazole based ratiometric fluorescent probe for the selective detection of sulfite ions in water was investigated. It shows large (pseudo) Stokes shifts (260 nm), high FRET efficiency, high selectivity and sensitivity. A distinct color change from red to colorless was observed and importantly, it proves to be a convenient and efficient tool to detect the sulfite levels in sugar samples.

\section{Introduction}

Sulfites are widely applied in the production of foods, pharmaceutical products and beverages as antimicrobial agents, antioxidants and enzyme inhibitors. ${ }^{1}$ However, the levels of sulfites have been strictly controlled because of the harmful effects towards the human body, such as allergic reactions and food intolerance symptoms. ${ }^{2-4}$ Therefore, for food quality control and quality assurance, it is important to develop a lowcost, selective and sensitive method for sulfite determination.

Compared with several traditional methods such as electrochemistry and chromatography, fluorescent probes are particularly attractive due to their simplicity, high selectivity and high sensitivity. ${ }^{5}$ Many fluorescent probes are reported to detect sulfites based on the changes of emission intensity. ${ }^{6}$ However, the signal output of these intensity-based fluorescent probes can be affected by instrumental factors, environmental effects and probe concentrations. ${ }^{7}$ Therefore, ratiometric fluorescent probes which are independent of the environmental effects are more desirable. ${ }^{\mathbf{8 - 1 1}}$ Also, they have large Stokes shifts which can prevent serious self-quenching and fluorescence detection errors. So far, only a few well-behaved ratiometric probes for sulfite have been reported. ${ }^{\mathbf{1 2 - 2 6}}$ Herein, a new FRET based ratiometric fluorescent probe was designed (Scheme 1). A pyrido[1,2-a]benzimidazole fluorophore, due to its favorable photophysical properties, was selected as the donor. While a hemicyanine fluorophore of which the absorption band

${ }^{a}$ School of Chemistry and Pharmaceutical Engineering, Taishan Medical University, Taian, Shandong 271016, P. R. China. E-mail: geyanqing2016@126.com; Fax: +86538-6229741; Tel: +86-538-6229741

${ }^{b}$ School of Chemistry and Chemical Engineering, Liaocheng University, Liaocheng, Shandong 252000, P. R. China

$\dagger$ Electronic supplementary information (ESI) available: ${ }^{1} \mathrm{H}$ NMR, ${ }^{13} \mathrm{C}$ NMR and MS spectra of probe, and additional cell images. See DOI: 10.1039/c8ra08967a

\$ Equal contribution. overlapped well the emission band of the donor was chosen as the acceptor (Fig. $\mathrm{S} 1 \dagger$ ).

\section{Experimental}

\section{Reagents and instrumentation}

RF-5301PC luminescence spectrophotometer (Shimadzu) and UV-2600 spectrometer (Shimadzu) were used to measure the fluorescence and UV-vis absorption spectra, respectively. NMR spectra were recorded on a Bruker Avance $400(400 \mathrm{MHz})$ spectrometer (in $\mathrm{CDCl}_{3}$, TMS as an internal standard). All commercial reagents and solvents were used without further purification.

\section{Preparation of the probe PBI-S}

Compound 1 and compound 2 were synthesized according to the literature..$^{27,28}$ To a solution of compound $1(580 \mathrm{mg}, 2$ $\mathrm{mmol}$ ) in $20 \mathrm{~mL} \mathrm{CH} \mathrm{Cl}_{2}$ was added DMAP (60 mg, $0.4 \mathrm{mmol}$ ) and EDC (576 mg, $3.0 \mathrm{mmol}$ ). Then, compound 2 (744 mg, 12 $\mathrm{mmol}$ ) was added. The mixture was stirred for $12 \mathrm{~h}$ at room temperature. After removal of the solvent under reduced pressure, the crude probe was obtained, which was purified flash silica gel chromatography $\left(\mathrm{CH}_{3} \mathrm{OH}: \mathrm{CH}_{2} \mathrm{Cl}_{2}=1: 100\right)$ to afford pure probe PBI-S (purity: 98.6\%, $456 \mathrm{mg}$, yield: 71\%). ${ }^{1} \mathrm{H}$ NMR $\left(400 \mathrm{MHz}, \mathrm{CDCl}_{3}\right) \delta 8.55(\mathrm{~d}, J=8.0 \mathrm{~Hz}, 1 \mathrm{H}), 8.00(\mathrm{~d}, J=8.0 \mathrm{~Hz}$, $1 \mathrm{H}), 7.96$ (d, $J=8.0 \mathrm{~Hz}, 1 \mathrm{H}), 7.87$ (d, $J=8.0 \mathrm{~Hz}, 2 \mathrm{H}), 7.54(\mathrm{~m}$, $6 \mathrm{H}), 7.44(\mathrm{~m}, 2 \mathrm{H}), 6.95(\mathrm{~d}, J=8.0 \mathrm{~Hz}, 1 \mathrm{H}), 6.79(\mathrm{~d}, J=16.0 \mathrm{~Hz}$, $1 \mathrm{H}), 6.74(\mathrm{~d}, J=8.0 \mathrm{~Hz}, 2 \mathrm{H}), 3.92(\mathrm{~m}, 1 \mathrm{H}), 3.52(\mathrm{~m}, 2 \mathrm{H}), 3.24(\mathrm{~m}$,
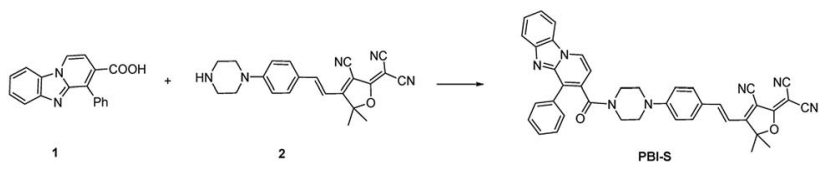

Scheme 1 Synthesis of probe PBI-S. 
1H), $3.12(\mathrm{~m}, 2 \mathrm{H}), 2.98(\mathrm{~m}, 1 \mathrm{H}), 2.18(\mathrm{~m}, 1 \mathrm{H}), 1.75(\mathrm{~s}, 6 \mathrm{H}) .{ }^{13} \mathrm{C}$ NMR $\left(100 \mathrm{MHz}, \mathrm{CDCl}_{3}\right) \delta 175.9,174.2,167.8,153.2,147.5,146.7$, $145.0,131.7,130.1,129.4,128.7,126.1,125.0$, 124.2, 122.0, 120.6, 114.4, 111.5, 111.0, 110.7, 110.6, 109.9, 97.2, 96.3, 46.5, 46.2, 45.0, 41.0, 26.7. HRMS: $642.2590\left([\mathrm{M}+\mathrm{H}]^{+}\right)$; calcd for $\mathrm{C}_{40} \mathrm{H}_{32} \mathrm{~N}_{7} \mathrm{O}_{2}: 642.2617$.

\section{Results and discussion}

PBI-S was synthesized by the classical condensation of compound $\mathbf{1}$ with compound $\mathbf{2}$ in one step in good yield (Scheme 1).

The solvent and effect of water content on fluorescence spectra of the probe was investigated firstly (Fig. S2 and S3†). Considering its better peak shapes, we chose the solvent ratio $(\mathrm{DMF} / \mathrm{PBS}=3: 7)$ as the vitro test solvent system.

The absorption band of PBI-S, attributing to hemicyanine and pyrido[1,2- $a$ ] benzimidazole moiety, centered at $556 \mathrm{~nm}$ and $334 \mathrm{~nm}$. When sodium sulfite was added gradually to the solution of PBI-S (DMF/PBS = 3:7), the absorption peak at $334 \mathrm{~nm}$ increased while the peak at $556 \mathrm{~nm}$ decreased (Fig. 1). Concomitantly, the solution turned from red to colorless in color, which proves that PBI-S could act as a "naked-eye" probe for $\mathrm{HSO}_{3}{ }^{-}$. It was calculated that the ratio of the absorbance at 334 and $556 \mathrm{~nm}$ displayed an over 300-fold enhancement, which indicates that PBI-S is capable for detecting sulfite by UVvis absorption.

Next, the fluorescence titration was conducted. The free PBIS displayed two obvious fluorescence bands at $465 \mathrm{~nm}$ and $640 \mathrm{~nm}$, which attributed to pyrido[1,2-a]benzimidazole and hemicyanine unit, respectively. Upon addition of $\mathrm{HSO}_{3}{ }^{-}$incrementally, fluorescence emission band at $465 \mathrm{~nm}$ increased

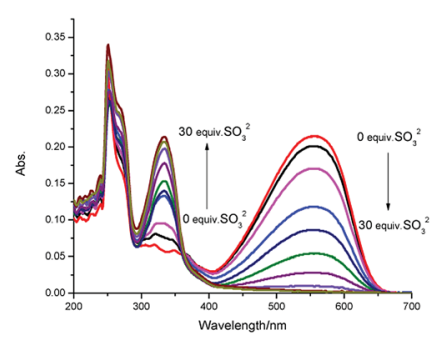

Fig. 1 Absorption spectra of PBI-S $(5 \mu \mathrm{M})$ upon addition of $\mathrm{HSO}_{3}{ }^{-}(150$ $\mu M)$ in DMF-PBS buffer solution $(3 / 7, v / v, p H=7.20)$.

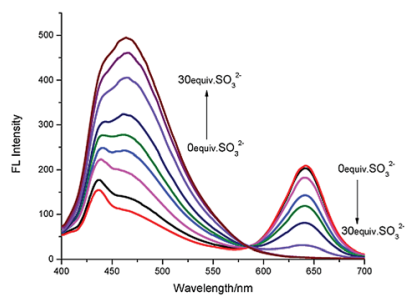

Fig. 2 Fluorescence spectra of PBI-S $(5 \mu \mathrm{M})$ upon addition of $\mathrm{HSO}_{3}{ }^{-}$ $(150 \mu \mathrm{M})$ in DMF-PBS buffer solution $(3 / 7, \mathrm{v} / \mathrm{v}, \mathrm{pH}=7.20),\left(\lambda_{\mathrm{ex}}=\right.$ $380 \mathrm{~nm}$, slit $=10 \mathrm{~nm} / 10 \mathrm{~nm}$ ).

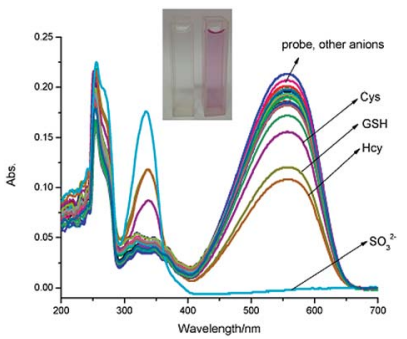

Fig. 3 UV-vis spectral changes of probe PBI-S $(5 \mu \mathrm{M})$ in the presence of various analytes $(150 \mu \mathrm{M})$.

gradually while the fluorescence at $640 \mathrm{~nm}$ decreased (Fig. 2), which implies that the acceptor moiety was destroyed by the reaction of the probe with $\mathrm{HSO}_{3}{ }^{-}$and the FRET between the donor and the acceptor was switched off.

The ratio of emission intensities at 465 and $640 \mathrm{~nm}\left(I_{465} / I_{640}\right)$ changed from 0.52 in the absence of $\mathrm{HSO}_{3}{ }^{-}$to 123.75 , a 238 -fold variation in the ratios. Furthermore, the emission ratio $\left(I_{465}\right)$ $I_{640}$ ) was found to increase linearly with the $\mathrm{HSO}_{3}{ }^{-}$concentration changed from 3 to $9 \mu \mathrm{M}$ (Fig. S4†). The detection limit was determined to be $62 \mathrm{nM}$ which is calculated by $3 \sigma / k$ (" $\sigma$ " is the standard deviation of 15 blank measurements, " $k$ " is the slope of the fitting line).

Then the selectivity of PBI-S toward sulfite over other relevant anions was conducted and it was observed that only by the addition of sulfite could the absorption and fluorescence change. While with other anions, no change in the UV and FL

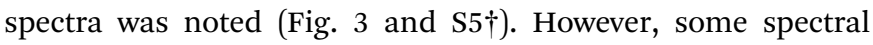
changes in GSH, Hcy and Cys were observed due to nucleophilic property of the $\mathrm{SH}$ group in them.

Furthermore, we studied the responses of PBI-S to the sulfite in the presence of the other competitive anions (including $\mathrm{GSH}$, Hcy and Cys). It was observed that when the other anions were added subsequently, the fluorescence emission ratios $\left(I_{465} / I_{640}\right)$ were not influenced (Fig. S6†).

As shown in Fig. S7, $\uparrow$ the probe was stable and can function well over a wide range of $\mathrm{pH}$ (6.0-10.0). Time-dependent fluorescence response to $\mathrm{SO}_{3}{ }^{2-}$ was also carried out (Fig. $\left.\mathrm{S} 8 \dagger\right)$. The reaction could be completed within $2 \mathrm{~min}\left(50 \mathrm{eq} . \mathrm{SO}_{3}{ }^{2-}\right)$. Such a rapid response is appealing for real-time detection.

The supposed mechanism is shown in Scheme 2. For the probe alone, FRET between the pyrido[1,2- $a$ ] benzimidazole and hemicyanine moiety resulted in red emission from hemicyanine. Upon the addition of $\mathrm{HSO}_{3}{ }^{-}$, the energy transfer from pyrido[1,2-a]benzimidazole donor to hemicyanine acceptor was

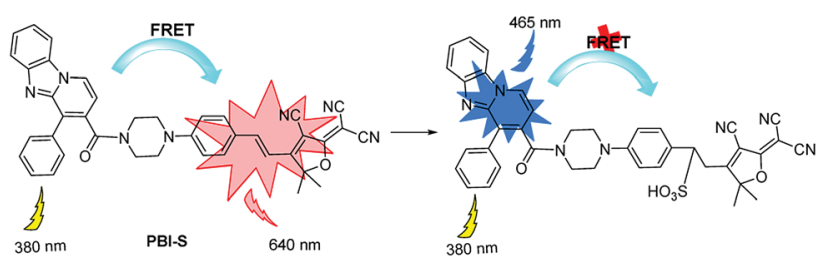

Scheme 2 Proposed mechanism of probe. 
Table 1 Concentration of the sulfite in sugar samples ${ }^{a}$

\begin{tabular}{lllrr}
\hline Sample & $\mathrm{HSO}_{3}{ }^{-}$level $\pm \mathrm{SD}\left(\mu \mathrm{mol} \mathrm{L}{ }^{-1}\right)$ & Added $\left(\mu \mathrm{mol} \mathrm{L}{ }^{-1}\right)$ & Found $\left.\pm \mathrm{SD}(\mu \mathrm{mol} \mathrm{L})^{-1}\right)$ & Recovery $\pm \mathrm{SD}(\%)$ \\
\hline Crystal sugar & $0.63 \pm 0.048$ & 0.5 & $1.07 \pm 0.031$ & $94.69 \pm 2.6 \%$ \\
& & 1 & $1.58 \pm 0.036$ & $96.93 \pm 2.3 \%$ \\
Granulated sugar & $1.21 \pm 0.049$ & 0.5 & $1.80 \pm 0.026$ & $105.26 \pm 0.51 \%$ \\
Soft sugar & & 1 & $2.04 \pm 0.030$ & $92.31 \pm 0.03 \%$ \\
& $0.76 \pm 0.045$ & 0.5 & $1.28 \pm 0.0140$ & $101.16 \pm 3.3 \%$ \\
& & 1 & $1.70 \pm 0.0127$ & $96.59 \pm 3.5 \%$
\end{tabular}

${ }^{a}$ The results were presented as means $\pm \mathrm{SE}$ with replicates $n=5$.

interrupted because of the breakage of $\mathrm{C}=\mathrm{C}$ bond by the addition reaction with $\mathrm{HSO}_{3}{ }^{-}$. The MS spectra of the reaction product also supported the deduction (calcd for $\mathrm{C}_{40} \mathrm{H}_{34} \mathrm{~N}_{7} \mathrm{O}_{5} \mathrm{~S}$ : 723.2342, found 723.2334, Fig. S9 and S10 $†$ ).

Finally, PBI-S was applied to detect sulfite in sample analysis of commercially purchased granulated sugar, crystal sugar, and soft sugar. The sugar $(5.0 \mathrm{~g})$ was dissolved in deionized water and then was diluted to $10 \mathrm{~mL}$. To the solution of the probe PBI$\mathbf{S}(5 \mu \mathrm{M})$ in the DMF/PBS buffer $(\mathrm{DMF} / \mathrm{PBS}=3: 7, \mathrm{pH} 7.20,10$ $\mathrm{mM}$ ), aliquots of the sugar solution were added. As shown in Table 1 , the $\mathrm{HSO}_{3}{ }^{-}$concentration in sugar was successfully determined by the probe PBI-S with good recovery.

It was calculated that the $\mathrm{HSO}_{3}{ }^{-}$concentration in the three sugar samples were $0.79,1.52$, and $0.96 \mathrm{mg} \mathrm{kg}^{-1}$, respectively. A traditional titration method was carried out to test the accuracy of this method and Table $\mathrm{S} 1 \dagger$ showed that results of the two methods were equivalent.

\section{Conclusions}

In summary, we have developed a new fluorophore pyrido[1,2- $a$ ] benzimidazole based ratiometric fluorescent probe for selective detection of sulfite ion in water. It shows large (pseudo) Stokes shifts (260 nm), high FRET efficiency, high selectivity and sensitivity. A distinct color change from red to colorless was observed and importantly, it proves to be a convenient and efficient tool to detect the sulfite levels in sugar samples.

\section{Conflicts of interest}

There are no conflicts to declare.

\section{Acknowledgements}

This work was supported by the Science Fund of Shandong Province for Excellent Young Scholars (ZR2017JL015) and the Natural Science Foundation of China (21602153 and 11574009).

\section{Notes and references}

1 J. L. Wang, Y. F. Hao, H. Wang, S. X. Yang, H. Y. Tian, B. G. Sun and Y. G. Liu, Rapidly responsive and highly selective fluorescent probe for bisulfite detection in food, $J$. Agric. Food Chem., 2017, 65, 2883-2887.
2 M. G. Choi, J. Y. Hwang, S. Y. Eor and S. K. Chang, Chromogenic and fluorogenic signaling of sulfite by selective deprotection of resorufin levulinate, Org. Lett., 2010, 24, 5624-5627.

3 X. F. Gu, C. H. Liu, Y. C. Zhu and Y. Z. Zhu, A borondipyrromethene-based fluorescent probe for colorimetric and ratiometric detection of sulfite, J. Agric. Food Chem., 2011, 59, 11935-11939.

4 K. Y. Chen, Y. Guo, Z. H. Lu, B. Q. Yang and Z. Shi, Novel coumarin-based fluorescent probe for selective detection of bisulfite anion in water, Chin. J. Chem., 2010, 28, 55-60.

5 Y. M. Yang, Q. Zhao, W. Feng and F. Y. Li, Luminescent chemodosimeters for bioimaging, Chem. Rev., 2013, 113, 192-270.

6 V. S. Lin, W. Chen, M. Xian and C. J. Chang, Chemical probes for molecular imaging and detection of hydrogen sulfide and reactive sulfur species in biological systems, Chem. Soc. Rev., 2014, 44, 4596-4618.

7 L. Yuan, W. Y. Lin, K. B. Zheng and S. S. Zhu, FRET-based small-molecule fluorescent probes: rational design and bioimaging applications, Acc. Chem. Res., 2013, 46, 14621473.

8 X. L. Zheng, R. X. Ji, X. Q. Cao and Y. Q. Ge, FRET-based ratiometric fluorescent probe for $\mathrm{Cu}^{2+}$ with a new indolizine fluorophore, Anal. Chim. Acta, 2017, 978, 48-54.

9 Y. Q. Ge, R. X. Ji, S. L. Shen and X. Q. Cao, A ratiometric fluorescent probe for sensing $\mathrm{Cu}^{2+}$ based on new imidazo [1,5-a]pyridine fluorescent dye, Sens. Actuators, B, 2017, 245, 875-881.

10 Y. Q. Ge, X. J. Xing, A. K. Liu, R. X. Ji, S. L. Shen and X. Q. Cao, A novel imidazo[1,5-a]pyridine-rhodamine FRET system as an efficient ratiometric fluorescent probe for $\mathrm{Hg}^{2+}$ in living cells, Dyes Pigm., 2017, 146, 136-142.

11 R. X. Ji, A. K. Liu, S. L. Shen, X. Q. Cao, F. Li and Y. Q. Ge, An indolizine-rhodamine based FRET fluorescence sensor for highly sensitive and selective detection of $\mathrm{Hg}^{2+}$ in living cells, RSC Adv., 2017, 7, 40829-40833.

12 X. F. Yang, M. L. Zhao and G. Wang, A rhodamine-based fluorescent probe selective for bisulfite anion in aqueous ethanol media, Sens. Actuators, B, 2011, 152, 8-13.

13 Y. Q. Sun, P. Wang, J. Liu, J. Y. Zhang and W. Guo, A fluorescent turn-on probe for bisulfite based on hydrogen bond-inhibited $\mathrm{C}=\mathrm{N}$ isomerization mechanism, Analyst, 2012, 137, 3430-3433. 
14 H. Y. Tian, J. H. Qian, Q. Sun, H. Y. Bai and W. B. Zhang, Colorimetric and ratiometric fluorescent detection of sulfite in water via cationic surfactant-promoted addition of sulfite to $\alpha, \beta$-unsaturated ketone, Anal. Chim. Acta, 2013, 788, 165-170.

15 M. Y. Wu, K. Li, C. Y. Li, J. T. Hou and X. Q. Yu, A watersoluble near-infrared probe for colorimetric and ratiometric sensing of $\mathrm{SO}_{2}$ derivatives in living cells, Chem. Commun., 2014, 50, 183-185.

16 Z. X. Liu, S. J. Guo, J. Y. Piao, X. Zhou and X. Wu, A reversible fluorescent probe for circulatory detection of sulfites through a redox-based tandem reaction, $R S C A d v ., 2014,4$, 54554-54557.

17 W. Xu, C. L. Teoh, J. J. Peng, D. D. Su, L. Yuan and Y. T. Chang, A mitochondria-targeted ratiometric fluorescent probe to monitor endogenously generated sulfur dioxide derivatives in living cells, Biomaterials, 2015, 56, 1-9.

18 Y. Liu, K. Li, M. Y. Wu, Y. H. Liu, Y. M. Xie and X. Q. Yu, A mitochondria-targeted colorimetric and ratiometric fluorescent probe for biological $\mathrm{SO}_{2}$ derivatives in living cells, Chem. Commun., 2015, 51, 10236-10239.

19 X. J. Liu, Q. W. Yang, W. Q. Chen, L. N. Mo, S. Chen, J. Kang and X. Z. Song, A ratiometric fluorescent probe for rapid, sensitive and selective detection of sulfur dioxide with large Stokes shifts by single wavelength excitation, Org. Biomol. Chem., 2015, 32, 8663-8668.

20 B. Roubinet, L. Bailly, E. Petit, P. Y. Renard and A. Romieu, A FRET-based probe for fluorescence sensing of sulfide/sulfite analytes, using a novel long-wavelength water-soluble 7hydroxycoumarin as reporter fluorophore, Tetrahedron Lett., 2015, 56, 1015-1019.
21 W. L. Wu, H. L. Ma, M. F. Huang, J. Y. Miao and B. X. Zhao, Mitochondria-targeted ratiometric fluorescent probe based on FRET for bisulfite, Sens. Actuators, B, 2017, 241, 239-244.

22 Z. Chen, F. Z. Chen, Y. C. Sun, H. Liu, H. P. He, X. H. Zhang and S. F. Wang, A novel ratiometric fluorescent probe for selective detection of bisulfite in living cells, RSC Adv., 2017, 7, 2573-2577.

23 Y. Yao, Q. Sun, Z. Chena, R. Huang, W. Zhang and J. Qian, A mitochondria-targeted near infrared ratiometric fluorescent probe for the detection of sulfite in aqueous and in living cells, Talanta, 2018, 189, 429-436.

24 J. Xu, D. J. Zheng, M. M. Su, Y. C. Chen, Q. C. Jiao, Y. S. Yang and H. L. Zhu, A rapid cell-permeating turn-on probe for sensitive and selective detection of sulfite in living cells, Org. Biomol. Chem., 2018, 16, 6940-6946.

25 K. Dou, G. Chen, F. Yu, Z. Sun, G. Li, X. Zhao, L. Chen and J. You, A two-photon ratiometric fluorescent probe for the synergistic detection of the mitochondrial $\mathrm{SO}_{2} / \mathrm{HClO}$ crosstalk in cells and in vivo, J. Mater. Chem. B, 2017, 5, 8389-8398.

26 K. Dou, Q. Fu, G. Chen, F. Yu, Y. Liu, Z. Cao, G. Li, X. Zhao, L. Xia, L. Chen, H. Wang and J. You, A novel dual-ratiometric response fluorescent probe for $\mathrm{SO}_{2} / \mathrm{ClO}^{-}$detection in cells and in vivo and its application in exploring the dichotomous role of $\mathrm{SO}_{2}$ under the $\mathrm{ClO}^{-}$induced oxidative stress, Biomaterials, 2017, 133, 82-93.

27 Y. Q. Ge, X. L. Zheng, R. X. Ji, S. L. Shen and X. Q. Cao, A new pyrido[1,2-a]benzimidazole-rhodamine FRET system as an efficient ratiometric fluorescent probe for $\mathrm{Cu}^{2+}$ in living cells, Anal. Chim. Acta, 2017, 965, 103-110.

28 Y. Q. Ge, A. K. Liu, R. X. Ji, S. L. Shen and X. Q. Cao, Detection of $\mathrm{Hg}^{2+}$ by a FRET ratiometric fluorescent probe based on a novel pyrido[1,2-a]benzimidazole rhodamine system, Sens. Actuators, B, 2017, 251, 410-415. 